\title{
Cuidar na situação de adoecimento raro: vivência da família e sua busca por amparo dos serviços de saúde'
}

\section{Care in the rare illness situation: family experience and problem-solving capacity of health services}

\author{
Juliana de Lima Soares \\ Universidade Federal do Mato Grosso. Cuiabá, MT, Brasil. \\ E-mail: juhsoaressळyahoo.com.br \\ Laura Filomena Santos de Araújo \\ Universidade Federal do Mato Grosso. Cuiabá, MT, Brasil. \\ E-mail: laurafilıyahoo.com.br
}

\section{Roseney Bellato}

Universidade Federal do Mato Grosso. Cuiabá, MT, Brasil.

E-mail: roseneybellato®gmail.com

\section{Correspondência}

Juliana de Lima Soares

Universidade Federal de Mato Grosso. Faculdade de Enfermagem. Avenida Fernando Correa da Costa, 2367, Boa Esperança.

Cuiabá, MT, Brasil. CEP 78060-900.

\section{Resumo}

Compreender a vivência familiar no cuidado à criança com síndrome rara, bem como, sua busca por amparo dos serviços e profissionais de saúde. Estudo compreensivo desenvolvido junto à família constituída, nuclearmente, por Pedro e Luisa, pais de Theo, que nasceu com síndrome raríssima e neurodegenerativa. As estratégias metodológicas incluíram a História de Vida operacionalizada pela Entrevista em Profundidade e Observação. 0 campo compreendeu junho de 2015 a janeiro de 2016 e o material empírico foi organizado no Diário de Pesquisa. Realizamos sua leitura atentiva, atribuindo diferenciação por cor aos significados dos trechos narrados. A pesquisa matricial a qual este estudo se vincula tem aprovação ética sob o $n^{0}$ 951.101/CEP-HUJM/2015. Os cuidados oferecidos pela família são preparados com esmero e de modo integrativo, tendo como foco o bem-estar de Theo e o seu desenvolvimento naquilo que lhe é possível. Essa perspectiva integrativa se distancia daquela dos serviços e profissionais de saúde que oferecem respostas estritamente pontuais, direcionadas ao que é demandado em dado momento. Para ampliar a capacidade resolutiva, os serviços/profissionais de saúde precisam pôr em movimento noções diferenciadas de tempo e temporalidade, de maneira a reconsiderar os tempos protocolares e rigidamente formalizados, num esforço de abarcar a temporalidade do viver e do cuidar de crianças com outras normalidades.

Palavras-chave: Família; Cuidadores Familiares; Atividades Cotidianas; Síndrome.

1 Fonte de financiamento: Coordenação de Aperfeiçoamento de Pessoal de Nível Superior (Capes). 


\section{Abstract}

Understanding the family experience in the care of a rare syndrome child and their search for support from the health services and professionals. Comprehensive study developed on the nuclear family formed by Pedro and Jessica, Theo's parents, a child who was born with rare and neurodegenerative syndrome. The methodological strategies included the Life History operationalized by In-depth Interview and Observation. The fieldwork was performed from June/2015 to January/2016 and the empirical material was compiled in a Research Journal. Performing an attentive reading, we assigned a different color to the meanings of the narrated excerpts. The matrix research which this study is linked has ethical approval under the number 951101/CEP-HUJM/2015. The family solicitude is careful and integrative, focusing on Theo's well-being and development, as possible. This integrative perspective is different from the one held by the health services and professionals that offer strictly specific responses to the momentary demands. To increase the response capacity, services and health professionals need to set in motion different notions of time and temporality, in order to reconsider the protocol and rigidly formalized times in an effort to cover the living temporality and the children care, including children with other normalities.

Keywords: Family; Family Caregivers; Daily Life Activities; Syndrome.

\section{Introdução}

A família, independente de sua configuração, constitui-se pilar sustentador para o nascimento, crescimento e desenvolvimento de seus entes, caracterizando-se como lugar de apoio mútuo, onde o cuidado "da" e "para" vida acontece (Bellato et al., 2016). Isso significa dizer que a família oferece cuidados que perpassam as relações familiares e abarcam as múltiplas dimensões do viver, o que a torna a principal cuidadora de cada um de seus entes ao longo do tempo e das gerações.

$\mathrm{O}$ adoecimento, parte intrínseca do movimento da vida e do viver, exige que a família mobilize seus potenciais de cuidado de modo mais intenso, em especial quando a doença apresenta caráter crônico, que pode cursar por longo tempo ou por toda a vida. 0 adoecimento toma relevo na vida das pessoas como situação crônica - termo que busca ampliar o olhar para os múltiplos contingenciamentos que pesam sobre as pessoas e suas famílias ao vivenciarem o adoecer, bem como suas possibilidades concretas de cuidarem e serem cuidadas (Bellato; Araújo, 2015). Buscamos abarcar, portanto, a dinamicidade do adoecer, cuidar e se cuidar como experiência singular e pessoalizada no tempo-espaço da família; e, por assim ser, descrita e refletida na perspectiva privilegiada dos entes que, nuclearmente, a compõem.

Este estudo trata da situação crônica por doença congênita, visto que há peculiaridades inerentes ao ser gerado e nascer adoecido, implicando em intensa ressignificação pelos pais, no que toca à vida e o cuidado ao filho. Tal situação, ganha maior expressão quando o adoecimento se constitui por uma síndrome raríssima que limita o próprio tempo do viver da criança, suscitando na família uma perspectiva de futuro incerto.

As consequências que a raridade de um adoecimento instaura no bojo familiar carregam consigo especificidades que se acrescem ao adoecer. Os pais, muitas vezes, precisam tomar decisões imediatas sobre o tratamento de seu filho ou, ainda, enfrentar uma situação de letalidade ou incapacidades que os obrigam a remodelar suas expectativas (González-Lamuño; Fuentes, 2008). 
No âmbito da assistência profissional, tão requerida nas situações de doença rara, a discussão é relativamente recente e vem ganhando força no Brasil, principalmente a partir da vigência da Portaria $n^{0} 199$, de 30 de janeiro de 2014, que institui a Política Nacional de Atenção Integral às Pessoas com Doenças Raras. Tal política define, em seu artigo $3^{\circ}$, que "considera-se doença rara aquela que afeta até 65 pessoas em cada 100.000 indivíduos, ou seja, 1,3 pessoas para cada 2.ooo indivíduos" (Brasil, 2014, p. 45). E tem por objetivo "reduzir a mortalidade, contribuir para a redução da morbimortalidade e das manifestações secundárias e a melhoria da qualidade de vida das pessoas, por meio de ações de promoção, prevenção, detecção precoce, tratamento oportuno redução de incapacidade e cuidados paliativos” (Brasil, 2014, p. 45).

Para tanto, distribui responsabilidades aos diversos órgãos do Estado que incluem desde a garantia de serviços de saúde e recursos humanos, até mecanismos de monitoramento, com vistas à melhoria da qualidade das ações (Brasil, 2014). 0 panorama brasileiro, entretanto, ainda se distancia do que está preconizado nesse documento, sendo que a comunidade científica e, principalmente, os profissionais atuantes nos serviços de saúde dispõem de conhecimentos restritos no que tange as doenças raras. Tais fatores contribuem para que o sistema de saúde, tanto em sua dimensão pública quanto privada, ofereça cobertura inadequada às necessidades das famílias que vivenciam tal situação (Portugal; Alves, 2015).

Sabemos que vários são os elementos que pesam na assistência às pessoas com doenças raras, e os estudos científicos que se configuram como apoiadores das práticas profissionais em saúde são, ainda, limitados em relação a este tema, dificultando o diagnóstico médico, o tratamento e a manutenção da assistência ao longo do tempo, dentre outros. Destacam-se, também, os estudos sobre doenças raras que, majoritariamente, apontam a perspectiva da abordagem clínica - estando pautados em estudos de caso da doença -, sendo ainda escassos aqueles que tratem do modo como o adoecimento raro afeta a vida da pessoa adoecida e de sua família, aspecto que se reflete, sobremaneira, na possibilidade de apoio ao cuidado familiar; conforme discorreremos neste artigo.

Nesse sentido, a abordagem que trazemos constitui-se em importante contribuição, por desenvolver-se sob a perspectiva privilegiada de uma família que vivencia o adoecimento de seu único filho pela raríssima Síndrome de Schinzel-Giedion (SSG). Tal síndrome foi descrita pela primeira vez em 1978 por dois pesquisadores, Albert Schinzel e Andreas Giedion, sendo caracterizada por uma desordem genética autossômica dominante (Hoischen et al., 2010) que acarreta inúmeros comprometimentos à vida e a saúde do recém-nascido.

Por se conformar como um adoecimento congênito, permanente e raro, a SSG impõe aos pais uma situação inesperada de cuidado ao novo ente familiar. Desse modo, é necessário intenso e constante esforço na busca por amparo de diferentes ordens e em diferentes lugares, que possam auxiliá-los na provisão do melhor cuidado ao filho. A família precisa ainda lidar com a gravidade da doença e o saber de sua letalidade, o que pode repercutir em uma cascata de sentimentos em relação ao filho e ao amanhã incerto que se descortina à sua frente.

Assim, objetivamos compreender a vivência familiar no cuidado à criança com síndrome rara, bem como, sua busca por amparo dos serviços e profissionais de saúde.

\section{Metodologia}

Trata-se de estudo de abordagem compreensiva, entendida como a postura do pesquisador frente ao outro, à vida e às formas de conhecer, fazendo-se em conformidade ao modo de compreender o ser humano em sua incompletude e impermanência (Bellato; Araújo, 2015). Em consonância com essa abordagem, o estudo foi desenvolvido sob a ótica do "estudo de situação”, cujo princípio é o de debruçarmo-nos no universo do cotidiano familiar, na tentativa de conhecê-lo de maneira aprofundada (Dolina et al., 2014), podendo traçar algumas inferências mais abrangentes a partir desta microrrealidade (Minayo, 2010).

No âmbito mais geral, este estudo se reporta aos critérios de inclusão da pesquisa matricial a 
qual se vincula, quais sejam: a) famílias residentes no estado de Mato Grosso, podendo participar os diferentes entes familiares, incluindo crianças, adolescentes, adultos e idosos; b) estar vivenciando uma situação de adoecimento crônico; c) utilizar serviços públicos de saúde em alguma medida ao longo do adoecimento.

A família participante é constituída, nuclearmente, por Pedro e Luisa, casal jovem de 23 e 24 anos, respectivamente, pais de Theo, nascido em junho de 2014, tendo completado um ano à época da recolha do material empírico. Theo é o único filho do casal e nasceu com a SSG, raríssima, congênita, neurodegenerativa e de prognóstico sombrio e incerto.

Para localização desta família lançamos mão de uma rede de informantes composta por docentes e alunos de enfermagem de uma instituição pública de ensino superior do estado de Mato Grosso, inseridos em diferentes situações de cuidado. Assim, diante da possibilidade de compreender a vivência familiar de um adoecimento raro, da juventude dos pais e de ser Theo o primeiro filho do casal, tivemos particular interesse em conhecer a família que foi, portanto, intencionalmente eleita como participante deste estudo. Desse modo, de antemão, admitimos e valorizamos a intencionalidade como elemento constituinte e direcionador da e na pesquisa de abordagem compreensiva; pois, o encontro com o outro conecta diferentes histórias e a pessoalidade do pesquisador também está envolvida quando nos debruçamos com uma atitude sensível frente às experiências humanas tão próximas de nossa realidade existencial (Bellato et al., 2016).

Corroboramos que o desenho da pesquisa se desenrola paulatinamente, ao se conferir certos relevos à complexa trama da experiência humana; e isso implica na sensibilidade do pesquisador em reconhecer o outro e, também, deste outro se dispor a dar-se a conhecer, relevando os significados dos acontecimentos que perpassam sua vida (Bellato; Araújo, 2015). Assim, na intenção de conhecer esse outro e apreender a vivência familiar de cuidado, empregamos diferentes estratégias metodológicas que, em conjunto, harmonizam-se ao nosso objeto de estudo.
A Entrevista em Profundidade é entendida como diálogo com intencionalidade (Minayo, 2010). Permite à pessoa discorrer livremente sobre sua experiência, sendo as indagações do pesquisador orientadas de modo a aprofundar, gradualmente, certos fios narrativos depreendidos da história (Araújo et al., 2013). Juntamente, empregamos a Observação, que nos possibilitou a apreensão dos modos e contextos peculiares de vida e cuidado, bem como de expressão, que vão além da fala, e que abrange e se entretece aos contextos variáveis nos quais o diálogo acontece (Araújo et al., 2013).

Ambas as estratégias compuseram a História de Vida da família de Theo, concebida por nós como modo privilegiado de apreender as experiências das pessoas e famílias, por implicar em alguém que se conta para o outro e para si mesmo, e em alguém que o escuta em sua vivência e a colore conferindo-lhe relevos a partir de elementos de sua própria vivência (Bellato; Araújo, 2015).

Todos os registros de observação e transcrição integral das narrativas compuseram o Diário de Pesquisa (Araújo et al., 2013), que consiste em 220 páginas digitadas em arquivo Microsoft Word Document (docx), em fonte Times New Roman, tamanho 12 e espaçamento simples entrelinhas. A recolha dessas informações ocorreu no período de junho de 2015 a janeiro de 2016, totalizando sete encontros. Destes, Pedro esteve presente em quatro e Luisa em todos; sendo que, nos dois primeiros meses, realizamos encontros semanais com a família buscando a aproximação da equipe pesquisadora com sua experiência de cuidado.

A compreensão do material empírico provocou um mergulho nas narrativas da família, por meio de leitura atentiva e minuciosa de todo o corpus da pesquisa, colorindo os trechos narrados, de modo a atribuir-lhes diferenciação segundo seus significados. Num esforço interpretativo desta experiência de vida, buscamos dar relevo aos elementos mais evidenciados pela família, contando e recontando momentos considerados importantes na vivência de cuidado ao filho. Assim, salientamos que a família tem referendado nossa "tradução" de sua experiência, naquilo que ela mesma trouxe como relevo 
para nós, o que se mostra validador do nosso esforço compreensivo.

Por meio da intensa aproximação e do distanciamento reflexivo sobre o corpus empírico, foram emergindo diversos eixos de sentido, dentre eles Busca por cuidado profissional especializado e medidas para alívio dos sintomas da síndrome. A partir deste, delineamos alguns desenhos analisadores, que refletissem tais buscas por cuidado, aos quais relacionamos o tempo vivido por Theo - nele indagando o tempo transcorrido de vida e as intervenções pontuais dos serviços. Idealizamos, então, um primeiro esboço da Linha da vida de criança em situação de adoecimento raro e as respostas dos serviços de saúde, que foi apresentado à família e complementado por ela, sendo suas várias versões aprimoradas, paulatinamente, no âmbito do grupo pesquisador. Para Araújo e Lacerda (2008) o desenho materializa imagens mentais, constituindo-se um signo interpretável como representação da realidade, evidenciando que existe intrínseca relação entre a imaginação e o desenvolvimento linguístico.

Destacamos que o desenho da linha do tempo do primeiro ano de vida de Theo foi construído a partir das narrativas da família e da consulta a documentos oferecidos pelo hospital à família, de modo a incluir as intervenções do sistema de saúde e os tempos em que elas ocorreram no bojo do viver de Theo e sua família. Desse modo, a construção de tal desenho analítico nos auxiliou na compreensão dos elementos constituidores do eixo de sentido em questão. Também possibilitou a apresentação imagético-sintetizadora do tempo decorrido da vida de Theo e, das intervenções dos serviços e profissionais de saúde e, especialmente, dos sentidos atribuídos pela família às situações que se descortinavam com a chegada de seu bebê.

Este estudo respeita e atende as prerrogativas éticas previstas na Resolução n 466/2012 (Brasil, 2013), sendo a pesquisa matricial, a qual se vincula, aprovada sob o $\mathrm{n}^{\circ}$ 951.101/CEP-HUJM/2015. Os nomes verdadeiros dos participantes, instituições e pessoas mencionadas foram mantidos em sigilo, respeitando o preceito do anonimato.

\section{Resultados}

As narrativas dos pais de Theo nos evidenciaram uma peregrinação intensa pelos diversos serviços de saúde, acionando diferentes profissionais, na tentativa de obter algum auxílio no oferecimento do melhor cuidado ao filho. Cientes da curta expectativa de vida imposta pela SSG, Luisa e Pedro têm postura extremamente ativa, empreendendo percursos que ultrapassam, inclusive, os limites geográficos do estado onde residem.

Na intenção de dar visibilidade a esse movimento de busca por atenção profissional resolutiva, num tempo relativamente curto, apresentamos a Linha da vida de criança em situação de adoecimento raro e as respostas dos serviços de saúde. Tal linha é escandida mês a mês de forma a possibilitar a apreensão espacial do tempo de vida de Theo - pouco mais de um ano, datando nele os marcadores de eventos importantes do seu acompanhamento pelos diversos profissionais de saúde. Para tanto, empregamos letras maiúsculas do alfabeto, de A à L. Apresentamos, também, trechos de narrativas dos pais relacionando-os a tais marcadores, de modo a explicitar os sentidos atribuídos pela família a esses acontecimentos. 


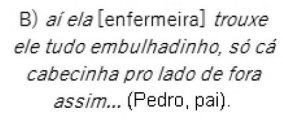

B) ai ela [enfermeira] trouxe ele tudo embulhadinho, só cá

cabecinha pro lado de fora assim... (Pedro, pai).

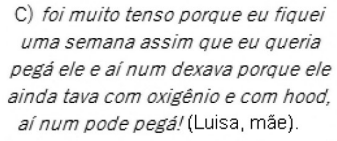

C) foi muito tenso porque eu fiquei uma semana assim que eu queria pegá ele e ai num dexava porque ele ainda tava com oxigênio e com hood, ai num pode pegá! (Luisa, mãe)

D) Ele [geneticista] falô: ó... tudo que ele tem se encaixa nessa sindrome, mas assim... A gente vai fazer alguns exames [...] Varei a noite pesquisaaano tal, procuraaano tal... e ai a gente [se emociona um pouco]... Eu vô chorá algumas vezes ai [...] Aieu comecei a pesquisá, aquela locura toda e tal[...] vinha uma coisa ruim e vinha uma coisa pior atrás da outra né? (Pedro, pai).

E) ele [Ricardo] fez de manhãe a noite ele foi embora, lembra? (Luisa, mãe).

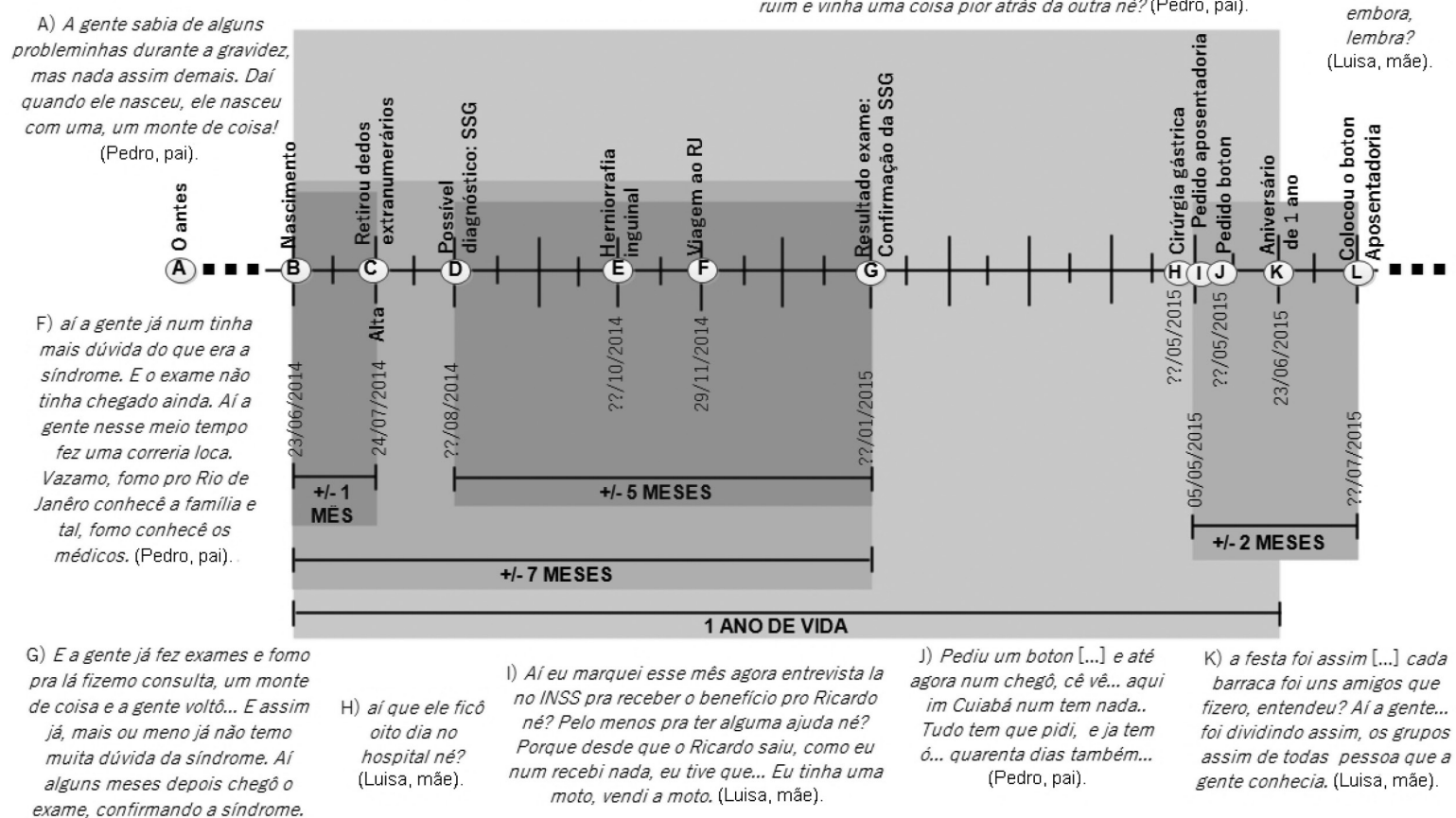

SOARES, J. L. Linha da vida de criança em situação de adoecimento raro e as respostas dos serviços de saúde. 2015.

Antes mesmo do nascimento de Theo, o casal foi recebendo informações pontuais sobre a possibilidade de seu bebê nascer com algumas alterações (Figura 1, marcador A). Com as posteriores consultas de pré-natal e exames de ultrassonografia, modificações como a polidactilia e alterações na formação dos rins e do coração do bebê foram sendo descobertas. Diante desse quadro, o médico responsável pelo pré-natal de Luisa sugeriu a possibilidade de Theo ter alguma síndrome, até então desconhecida por eles.

O nascimento de Theo (Figura 1, marcador B) constituiu-se um momento de grande celebração e felicidade para os pais e familiares, mas também se caracterizou pela hora em que as suposições saíram do campo das possibilidades e ocuparam lugar preponderante na concretude da vida:

$\varepsilon$ depois a enfermera veio chamá pro lado de fora assim, lá na recepção, aí ela falô: "Ah Theo já nasceu, o nenê já nasceu” [...] aí ela falô:
"Não, ta tudo bem e tal, só que o neném nasceu assim, assim assado"... cheio de problema! E aí perguntô se eu queria vê né, eu falei: "Lógico! Quero vêné?". Aí ela falô: "mais tem que sê muito rápido que ele tem que subi pra UTI direto". (Pedro, pai)

Devido aos inúmeros comprometimentos de saúde, o primeiro mês de vida de Theo transcorreu na Unidade de Terapia Intensiva Neonatal (Figura 1, marcadores B-C). Este foi um período de grande aflição para os pais que permaneceram indo e vindo do hospital, diariamente:

Trinta e quatro dias na UTI. [...] $\varepsilon$ aí todo dia a gente tem que ir na UTI, a gente ia no horário, de manhã, a tarde e a noite, né?! (Pedro, pai)

E foi necessário revezamento para as visitas, ajustando o cotidiano a essa demanda, como bem mostra Luisa: 
Mais aí, no começo eu ia com ele [Pedro]. Eu via ele [Theo] só um horário, Pedro que trabalhava lá perto. Aí Pedro via ele duas vezes, de manhã e a tarde. Aí como eu ainda tava operada, ele ia me buscá só um horário. (Luisa, mãe)

As dificuldades ultrapassavam o limite daquilo que o casal tinha como expectativa de proximidade e cuidado com seu filho, necessitando que ambos ressignificassem suas perspectivas de parentalidade às primeiras exigências do adoecimento. Os artefatos tecnológicos de sustentação e apoio à vida de Theo também se impunham como impeditivos dessa aproximação física e de cuidado pelos pais, situação mal sustentada pela equipe de saúde no sentido de minimizar seu sofrimento, visto que apenas a psicóloga se mostrou mais sensível a esse sofrimento, expresso no choro da mãe:

Depois duns quinze dias que eu comecei, tipo depois de uma semana que peguei no colo. [...] Aí peguei no colo depois de uma semana que a psicológa viu que eu tava chorano tudinho, quereno pegá ele... Aí ela foi e pediu pra liberá. [...] Aí foi... que eu, depois de uma semana que eu comecei a tentá dá de mamá a ele né? [Luisa para de falar e continua passando a mão em seu filho, retoma a fala em tom de voz baixo] Aí, foi um dia assim que eu tentei, aíno otro dia que eu ia pegá mesmo, assim, de ficá o dia todo, ele voltô pro hood, aí foi... Fiquei mais uns dia sem pegá ele [fala em tom entristecido]. (Luisa, mãe)

Ao longo do primeiro ano de vida, Theo também foi submetido a três cirurgias (Figura 1, marcadores C, E, H), sendo a primeira para correção e retirada dos dedos extranumerários das mãos, a segunda uma herniorrafia inguinal e a terceira uma cirurgia gástrica com fundoplicatura:

Ele já fez três cirurgia [...] então, tadinho... ele nasceu com seis dedinhos nas duas mãos, aí a gente tirou [risos][...] essa ele fez na UTI [risos]. $\varepsilon$ aí, logo depois... Ele nasceu com o testículo aqui em cima, não terminô de descer, aí ele teve hérnia inguinal. $\varepsilon$ a hérnia ficava descenu, era ocasio- nal né?! Aí depois começô descê o tempo todo e aí ficava uma bola aqui assim [mostra a região baixa do abdome], inchava tudo... Aí a gente já fez essa cirurgia também. Já fez, deu três ponto aqui assim [aponta a região do abdome onde foi feita a incisão]. E aí depois ele fez a gastro, agora [...] $e$ a gastro já foi um poquinho mais delicado porque foi com fundoplicatura, se fosse só a gastro era rapidinho fazia... (Pedro, pai)

A cirurgia para retirada dos dedos extranumerários teve significado para além da correção de um problema que poderia acarretar alguma dificuldade motora para Theo, pois tratou-se também de uma preocupação estética dos pais em relação ao filho, num esforço de buscar certa normalidade corporal. Já a decisão pelo procedimento de herniorrafia e de cirurgia gástrica foi por trazer benefícios para o crescimento e desenvolvimento de Theo, no sentido de lhe proporcionar alívio e conforto para um melhor viver. Luisa e Pedro seguem, a cada decisão a ser tomada, ponderando os ganhos proporcionais a Theo e, assim sendo, por vezes decidem abrir mão de procedimentos que lhe possam acarretar sofrimento, conforme expresso no trecho a seguir:

Ele nasceu com hipospádia também... Só que ele faz xixi, urina normal... então, a gente já descartou essa cirurgia. Nem vamo fazer mais porque é delicada né?! Então é sofrimento pra ele, num é necessidade... émais estética do que necessidade. (Pedro, pai)

Após esse primeiro mês internado, Theo teve alta do hospital maternidade (Figura 1, marcador C) e o casal pode levar seu filho para casa; entretanto, carregavam consigo muitas incertezas e angústias, pois não sabiam, exatamente, das condições de saúde do filho. Este foi um período intenso de "exame-consulta", o que denota a aflitiva busca pelo diagnóstico:

Aí... a gente saiu da UTI, começô um monte de médico... Nossa, nóis fazia acompanhamento com uns 1o, 12 médico... Sabe assim... parô minha vida, a dela [Luisa] e correno todo dia. Todo dia 
exame consulta, exame consulta. $E$ aífoi aparecendo os probleminha dele né... e aí a gente já foi se adaptano. Ta, aí foi que a gente começô fazê acompanhamento com geneticista [...] até então a gente sabia que ele tinha assim, que ele num era normal tal, tinha alguns probleminha, a gente num sabia o quê né? (Pedro, pai)

A intensa busca por atenção profissional realizada pelo casal também se direcionava à sintomatologia que Theo apresentava e aos modos de cuidá-lo, à medida de seu desenvolvimento e da progressão das consequências do adoecimento. Não percebiam, no entanto, similitude da situação vivida por Theo com a de outras crianças adoecidas; também os médicos não reconheciam casos clínicos que lhes servissem de referência. Em meio a tentativas, erros e acertos, o geneticista que acompanhava Theo sugeriu um possível diagnóstico (Figura 1, marcador D) a ser confirmado por meio de exame específico de sequenciamento parcial de um dos segmentos do gene mutado - o exon 4 do SETBP1, sendo o resultado obtido após noventa dias:

a gente foi lá e fez as consulta e tal e um mês depois... ele chamou a gente lá né? Aí quando a gente chegô lá, ele abriu o livro lá que ele estudô, pesquisô muito, tava escrevenu lá... o livro tudo em inglês. Ele falô: ó... tudo que ele tem se encaixa nessa sindrome, mas assim... A gente vaifazer alguns exames e tal e... Aí tipo... no final de semana, na sexta fera, ele começô a ter uns espasminho assim... e a gente achava que era quebrante. Foi aquela... toda: Ai é quebrante, é quebrante... Beleza, antes fosse né? Aí a gente chegô e começô a aumentá um poquinho né, aí a gente chegô lá, a gente foi falá pra ele [geneticista] disso. Ele falô: Ah primera coisa que aparece na síndrome aqui é CONVULSÃO! [...] aí ele foi pesquisá lá na onde que fazia exame da síndrome né? só tinha treis laboratório em São Paulo... e a gente foi pesquisô tal... [...] Noventa dias pra mandar o resultado do exame... (Pedro, pai)

Antevendo o diagnóstico da SSG, Luisa e Pedro se mobilizaram em busca de informações sobre a síndrome e tudo que pudesse lhes dizer em torno da mesma. Localizaram, por meio de busca na internet, apenas dois casos da síndrome em crianças brasileiras; e, então, contataram suas famílias por meio virtual e telefônico:

Aí a gente achô, a gente descubriu duas criancinha aqui no Brasil só que tinha... uma lá no Rio de Janêro e otra na Bahia. Aí tentei entrá em contato ca família e tal e num consigui, demorô uns dias né. Aí o pai do mininho lá do Rio de Janêro, ele criou um site... foi por onde eu discubri tudo, a maioria das coisa e tal. $\varepsilon$ aí tentei contato com ele, mandei mensagem lá no site e tal e uns dias depois eles responderam. [...] $O$ deles tinha... faleceu com dois ano e quatro dia, lá do Rio... Dois anos e quatros dias né?! $\varepsilon$ aí a gente consiguiu contato tamém... Com ele a gente consiguiu contato com a família da Bahia. Aí... tinha falecido tinha um mês tamém... [fala muito emocionada, como quem se segura para não chorar. Fica em silêncio por um tempo e retoma] Assim, era os dois que a gente sabia né? [Silêncio] Aí foi um choque maior ainda! (Pedro, pai)

Luisa e Pedro obtiveram apoio junto às duas famílias, além de muita informação sobre a síndrome e suas repercussões físicas. Foi possível ainda o reconhecimento da própria vivência em situações muito semelhantes àquelas vividas pelas famílias em decorrência da SSG. Esse reconhecimento motivou as famílias a compartilharem saberes e cuidados, dificuldades, aflições e perspectivas - o que foi deveras importante para que os pais de Theo vislumbrassem o melhor cuidado ao filho.

Ao mesmo tempo em que trouxe consolo à Luisa e Pedro, o fato de saberem que as duas crianças já haviam morrido provocou sentimentos de aflição em relação ao tempo do viver do próprio filho. Para os pais, os desencontros entre as expectativas e a realidade que se descortinava em relação a Theo, no que se refere ao seu primeiro ano de vida, davam-se em referência à morte prematura dos filhos das duas famílias por eles contatadas, inclusive com vívido sofrimento neste momento de encontro. 
Além disso, tal realidade também contrastava com os marcadores normais de crescimento e desenvolvimento infantil, aos quais Theo não se enquadrava. Diante disso, mais do que pressa, a família tinha urgência em cuidar de Theo, antecipando-se em cuidados às suas necessidades. Essa mesma urgência se fazia em relação a que ele fosse cuidado de uma perspectiva médica, embasada na prática e saber clínico.

Assim, procurando não desperdiçar o valioso tempo de vida do filho, Pedro e Luisa decidem conhecer a família do Rio de Janeiro pessoalmente (Figura 1, marcador F) - a convite da mesma -, buscando saber mais sobre a situação que começavam a se dar conta de que vivenciariam com o filho:

Aí tipo assim, ele foi crescendu, os problema foi aparecendu e tal... e aí a gente já num tinha mais dúvida tipo, do que era a síndrome. E o exame não tinha chegado ainda. Aía gente nesse meio tempo fez uma correria loca. Vazamo, fomo pro Rio de Janêro conhecê a família e tal, fomo conhecê os médicos. Aí lá que a gente conheceu a médica dele hoje, que a neurologista dele é de lá... [...] $\varepsilon$ a gente já fez exames e fomo pra lá fizemo consulta, um monte de coisa e a gente voltô... $\varepsilon$ assim já, mais ou meno já não teno muita dúvida da síndrome. Aí alguns meses depois chegô o exame, confirmando a síndrome... (Pedro, pai)

Na lógica dos profissionais de saúde, o tempo decorrido para a confirmação diagnóstica da existência da síndrome raríssima pode ser considerado relativamente curto: do nascimento de Theo até a suspeita diagnóstica elencada pelo geneticista transcorreram-se dois meses (Figura 1, marcador B a D); daí até a confirmação da SSG, passaram-se cinco meses (Figura 1, marcador D a G); e, então, após sete meses do nascimento da criança, o diagnóstico foi confirmado (Figura 1, marcador B a G).

No entanto, nestes sete meses vividos e compartilhados com Theo, ciente do incomensurável valor do tempo para sua vida, a família antecipou-se ao resultado do exame confirmatório da SSG e buscou, por vias próprias e pessoalizadas, aprender sobre a situação de adoecimento e reunir condições para melhor cuidar dele. Dentre tais condições, salien- tamos os pedidos de aposentadoria de Theo e da colocação do boton em sua gastrostomia (Figura 1, marcadores I, J), cuja reposta positiva demorou cerca de dois meses (Figura 1, marcador L).

Vale destacar, também, a festa de aniversário de um ano de vida de Theo (Figura 1, marcador K), no dia 23 de julho de 2015, momento bastante celebrado entre a família, os amigos e alguns dos profissionais que o acompanham, configurando-se em ocasião de comemoração da vida e da vitória sobre as dificuldades enfrentadas pela família. Tal festa, também foi importante para arrecadar fundos para o tratamento de Theo, já que o plano de saúde conveniado contratado pelos pais não cobre inteiramente toda a terapêutica exigida pelo adoecimento.

\section{Discussão}

As famílias cuidam de seus entes de modo amplo, abarcando as múltiplas dimensões do viver (Bellato et al., 2016). Tais cuidados configuram-se como permanentes e perduram ao longo do tempo e dos ciclos de vida, desde o nascimento, passando pela maturidade e velhice, até a morte; desse modo, a família oferece respostas às necessidades de seus entes das mais variadas naturezas. No entanto, há que se atentar para os potenciais de cuidado que disponha para tal, dado que estes sejam limitados e/ou podem se exaurir nas situações que perdurem, dentre elas, no adoecimento crônico raro vivenciado pela família deste estudo.

A família também lança mão de suas redes cuidativas e empreende buscas para prover o que de melhor conseguir ao ente adoecido. Tais buscas não se restringem a um determinado espaço institucional formalizado (Bellato et al., 2009), mas extrapolam-no com vistas a encontrar resolução para suas necessidades.

Nesse sentido, a família de Theo busca oferecer o melhor cuidado e, para engendrá-lo, mobiliza-se de modo a suplantar protocolos institucionais e condutas preditivas, envolvendo um complexo processo de interpretações e intuições sobre a situação de saúde do filho. Tal processo abarca o perceber e o pressentir, ou antessentir - no sentido da antecipação -, aquilo que será benéfico para Theo. 
O melhor cuidado envolve ponderações do que seja o mais conveniente, sensato, prudente e acertado a se fazer em relação a Theo, sendo que a tomada de decisão pelos pais considera uma complexa trama de elementos - destaque para o tempo de sua vida -, os quais são ajuizados em situação e se concretizam em consonância a cada necessidade que a criança apresenta, bem como ao conjunto delas, tomadas como referenciais. Tais ponderações são cogitadas e discutidas pelos pais, de modo a integrar possibilidades do viver bem e da diminuição do sofrimento decorrente do adoecer de Theo.

Assim, observamos um cuidado que se descortina da, na e para a vida do filho, buscando deixá-lo bem dentro das possibilidades que se apresentam no presente - aqui e agora -, não permitindo que a finitude, embora possa se apresentar como próxima, seja, para eles, um horizonte mortífero e limitante (Bellato; Araújo; 2015).

A experiência desta família nos ensina que o cuidado ocorre na vida, porque é provido no bojo do cotidiano do próprio viver e implica um olhar apurado que os pais vão desenvolvendo ao longo do tempo, capaz de perceber a minuciosidade das necessidades do filho. $O$ cuidado se faz também para a vida, pois visa promover as melhores condições para o viver bem e feliz, distanciando-se, portanto, da ideia do cuidado restrito ao adoecer. 0 cuidar da vida, por sua vez, carreia dimensões ainda mais ampliadas, projetando-se em direção ao amanhã, envolvendo os sonhos e expectativas que os pais tenham em relação à vida e ao futuro do filho.

Porquanto seja na vida compartilhada no cotidiano que o ser humano segue projetando-se em seu contínuo vir-a-ser, incita-nos a refletir sobre a temporalidade do vivido em família, lugar de construção e compartilhamento de projetos de felicidade. Corroboramos com Ayres (2009) quanto à noção de felicidade como experiência vivida e valorada positivamente e que, inclusive, independe daquilo que se convencionou considerar como completo bem-estar ou perfeita normalidade morfofuncional.

A família busca, assim, compreender a normalidade singular ou própria de Theo, que o difere de outras crianças de sua idade, lidando com suas peculiaridades e necessidades cotidianas na vida compartilhada. Souza e Lima (2007) destacam que o adoecimento, em especial o de caráter crônico, traz consigo a criação de novas normalidades de vida pelas pessoas, diferentes daquela anterior. Tais normalidades ajudam as pessoas no enfrentamento da situação crônica de adoecimento, pois ampliam suas possibilidades de melhor viverem e serem felizes.

Entretanto, esse modo próprio de ser e de viver de Theo também se configura como forte elemento de diferenciação. Frente a isso, os pais buscam acolher, com certa tranquilidade, os olhares e impressões das outras pessoas que não convivem com ele, na tentativa de minimizar os desconfortos em relação ao ser diferente, reduzindo, assim, sofrimentos relacionados a uma situação de não enquadramento do filho aos padrões impostos como normais, tanto pelos profissionais de saúde quanto pela sociedade em geral. Ressaltamos que tal diferenciação - embora bastante marcada, estruturalmente e funcionalmente, pelos profissionais de saúde no que se refere aos parâmetros de normalidade -, seja do crescimento ou do desenvolvimento de crianças com síndromes raras, parece não receber a mesma acolhida de modo a produzir e prover cuidados na medida de suas necessidades - ou seja, cuidados distintivos de sua pessoalidade -, e nem sempre geram maior efetividade nas práticas profissionais pela aplicação de discriminação positiva.

De maneira bastante importante, a temporalidade de vida própria dessas crianças precisaria ser considerada no oferecimento da atenção em saúde, ou seja, na medida e no tempo requeridos pelas necessidades que apresentam, ampliando, em certa medida, a capacidade resolutiva dos serviços de saúde. Estudo sobre a experiência familiar de cuidado à adolescente com adrenoleucodistrofia já alertava sobre a importância de se considerar o agravamento das necessidades de saúde, visto tratar-se de uma doença degenerativa, de modo que o cuidado oferecido seja progressivamente renovado ao longo do tempo e que os profissionais consigam apoiar as famílias neste cuidado (Nepomuceno et al., 2012).

A família faz o reconhecimento da normalidade própria de Theo a partir de outras crianças, empregando a partilha de experiências junto às outras famílias que também vivenciaram condição 
de adoecimento semelhante, o que, sobremaneira, constituiu apoios e ajudas imprescindíveis para melhor lidar com a situação de seu filho. Salientamos que reconhecer as singularidades no modo de adoecer do filho configura-se como fundamental na modelagem da provisão de cuidados, pois é a partir disso que a família se organiza para oferecer o que a criança necessita (Petean et al., 2016).

Por conseguinte, propomos aqui uma reflexão: que considerações podem ser feitas acerca da resolutividade das práticas oferecidas pelos serviços e profissionais de saúde, a partir da perspectiva privilegiada dos pais de uma criança que vivencia um adoecimento raríssimo e limitante na vida?

É possível encontrar alguns caminhos observando os modos de cuidar da família. Luisa e Pedro oferecem todos os cuidados requeridos pela tenra idade de Theo; e, de modo concomitante e imbricado, sobressaem aqueles exigidos pela própria SSG. Nessa confluência de cuidados intensos, contínuos e permanentes para sustentação da vida percebemos a preocupação acurada dos pais em relação ao tempo que transcorre, visto se tratar de uma síndrome que abrevia a expectativa de vida do filho. 0 engendramento de cuidados que incluam e integrem as necessidades do filho vão sendo, portanto, elaborados em situação, ou seja, a cada necessidade apresentada por Theo, os pais conjuntamente, ponderam sobre o melhor a ser feito para saná-la.

Assim, a gama complexa de cuidados oferecidos pela família - sejam aqueles que visam responder às necessidades da criança em tenra idade, sejam aqueles gerados pelo adoecimento - são realizados com esmero e de modo integrativo, tendo como foco o bem-estar de Theo e o seu desenvolvimento naquilo que lhe seja possível. Essa perspectiva integrativa se distancia, em grande medida, daquela dos serviços e dos profissionais de saúde que, por sua vez, oferecem respostas estritamente pontuais, direcionadas ao que é demandado em dado momento, pouco havendo de antecipação daquilo que será preciso ou uma percepção mais ampliada para o conjunto de necessidades que o "ser criança" e "estar seriamente adoecida" geram.

Observamos então, que lógicas bastante distintas orientam os profissionais de saúde e as famílias no oferecimento de cuidados. Enquanto estas buscam solução possível para as necessidades imbricadas no cotidiano do viver e do cuidar, os serviços/ profissionais de saúde oferecem certa capacidade de resolução para "problemas de saúde" recortados do rol mais amplo de necessidades que o adoecimento impõe (Bellato et al., 2009).

Assim, na medida em que os serviços e profissionais oferecem respostas ainda pouco resolutivas às necessidades exigidas pela situação de adoecimento de Theo, amplia-se, sobremaneira, o esforço de seus pais para tecer redes de apoio que lhes possam garantir certa efetividade do cuidado, ainda que por outras vias. Sobre isso, autores destacam que diante das respostas parciais do serviço de saúde, em que as pessoas não obtenham a solução necessária para seus problemas, é gerada uma situação de motor "propulsor" para empreendimentos de outras trajetórias de busca por cuidados (Bellato et al., 2009).

Apreendemos, então, que o cotidiano da vida e a constante ameaça a ela, imposta pela síndrome, pedem soluções mais urgentes do que os serviços e profissionais podem - e se dispõem - a oferecer. A família, por sua vez, aproveita e potencializa o tempo de vida de Theo, buscando conhecimento sobre a SSG por conta própria, de modo a encontrar soluções possíveis para cuidar do filho, integralmente. Dessa maneira, o elemento tempo toma especial relevo, uma vez que é nele que transcorre a vida de Theo e, também, é nele que habita o padecer dos amanhãs incertos impostos pela raríssima SSG.

O tempo, por conseguinte, tem valioso significado na concretude da realidade vivida e compartilhada em família, cabendo a Luisa e Pedro criarem e recriarem, cotidianamente, o melhor cuidado ao filho para potencializar seu tempo de vida. E, "potencializar o tempo de vida" de Theo tem, para os pais, tanto o sentido de ampliá-lo naquilo que for possível quanto de oferecer, nesse tempo possível, vida com qualidade. 0 tempo assume, portanto, o sentido de temporalidade, pois se trata do tempo afetivo e aflitivamente vivido no seu fluir inexorável, devendo, por isso, ser fruído de modo intenso. Tal aflição, com caráter de "tribulação angustiosa”, não se encerra sobre si mesma como dor aniquiladora; bem ao contrário, forja a perseverança, pois mira 
o horizonte da esperança; esta, reside no próprio ser do filho, Theo, e, também, nos pais que Luisa e Pedro almejam ser.

Nessa perspectiva, Dolina et al. (2014) tratam da temporalidade, atribuindo uma dimensão que se distancia da forma sequenciada de momentos distintos pela qual o tempo cronológico é marcado. E, diferentemente, espraia-se por reverberações de experiências nas quais passado-presente-futuro fluem em movimentos espirais.

Portanto, o tempo constitui-se dimensão ordenadora da vida humana e, no bojo do viver, a situação crônica de adoecimento - especialmente aquele de caráter raro, congênito e degenerativo também se expressa em temporalidades que dizem respeito à experiência cotidiana biográfica, vivida diferentemente por cada pessoa e cada família. 0 adoecer não se limita, portanto, à cronologia da evolução do agravo, nem à sua expressão clínica em períodos de agudização e estabilidade (Bellato et al., 2011). Ao contrário, ele ocorre no âmbito da temporalidade experiencial, que diz respeito ao tempo vivido e compartilhado, aquele que nós sentimos/significamos no concreto da realidade, e que está diante de nós desde o abrir dos olhos até quando os fechamos.

Essa temporalidade experiencial (Bellato et al., 2011) acaba sendo pouco perceptível aos profissionais e serviços de saúde, visto que a atenção organizada é ofertada nos estritos tempos protocolares e institucionais, cronologicamente demarcados. Por outro lado, o tempo do vivido se mostra variável, instável e incerto, conformando-se nos modos de cada pessoa perceber e conferir sentidos ao presente, conjugando-o ao seu passado e às antecipações futuras (Dolina et al., 2014).

Portanto, para ampliar sua capacidade resolutiva, os serviços e os profissionais de saúde precisam, também, pôr em movimento as noções diferenciadas de tempo e temporalidade, de maneira a reconsiderar os tempos protocolares e rigidamente formalizados que, via de regra, dirigem as ações e a organização dos processos assistenciais, num esforço necessário para abarcar a temporalidade do viver e do cuidar de crianças com outras normalidades. Lançamos, então, mais uma reflexão: o que são dois meses transcorridos em espera para uma criança como Theo?

Theo tem necessidades múltiplas, diferenciadas, além de marcadas por sua temporalidade singular, o que, por si, deveria mobilizar respostas ágeis, precisas e efetivas; no entanto, mesmo a garantia de seus direitos, já formalmente assegurados, seguiu a lógica do fluxo institucionalizado das demandas nos serviços a que cabem dar resposta. Se a aposentadoria visa oferecer algum amparo financeiro para o tempo possível e limitado de vida de Theo, deste tempo se esvaíram dois meses de espera. Seria importante que os trâmites burocráticos desta demanda ocorressem levando em consideração o tempo de vida que se abrevia pela própria gravidade imposta pela SSG para essa criança.

Outrossim, o tempo protocolarmente decorrido para a confirmação diagnóstica da síndrome raríssima, como é o caso da SSG, pode ser considerado rápido pelos serviços/profissionais de saúde. Entretanto, contrasta, gritantemente, com a temporalidade experienciada pela família, ao vivenciar cada dia que se inicia e se finda permeado por incertezas em relação ao dia seguinte, afligindo-se com um tempo que se projeta em amanhãs incertos, com os quais teve de aprender a lidar por conta própria.

Assim, entendemos que os serviços e os profissionais de saúde deparam com grandes desafios ao oferecer atenção profissional, visto que as práticas produzidas nesse âmbito precisam de sinergia com o cuidado familiar, reforçando e ampliando seus potenciais (Silva; Bellato; Araújo, 2013); e não exaurir esse cuidado pelo aumento no esforço da busca por cuidado efetivo e no tempo preciso às suas necessidades.

\section{Conclusão}

Este estudo buscou incitar reflexões importantes, tendo por base os muitos ensinamentos que a família nos proporciona acerca do seu modo personalíssimo de cuidar “da, para e na vida”, bem como das respostas, parciais e fragmentadas, que as práticas profissionais em saúde lhes oferecem para as necessidades sempre ampliadas e renovadas de seu filho. Desenvolvido na modalidade de estudo de 
situação de casal jovem que vivencia o adoecimento por síndrome rara e limitante da vida de seu único filho, não nos prestamos a generalizações, mas destacamos que as experiências vividas pelas pessoas possuem em sua essência a dimensão humana e que esta transversa diversas experiências familiares.

Os pais cuidam com um sentido aguçado e ampliado de cuidado que flui em diversas direções, espraiando-se pela vida de Theo, abarcando e integrando suas necessidades, de modo a respondê-las da melhor maneira possível. Em contrapartida, observam nos profissionais de saúde uma percepção difusa, que toma Theo no âmbito de seu "prazo de validade" e produz na família, em regra, o sentimento de desapoio e desesperança, dado que haveria muito o que ser feito na atenção ao filho acometido pela síndrome raríssima e letal.

A aproximação com outras famílias, que vivenciam ou vivenciaram situação semelhante, conformou-se num reencontro com a esperança, aprendendo e ensinando modos personalíssimos de cuidar do bem mais precioso - a vida do filho - na sua normalidade própria e no fluir do tempo que lhe for possível.

Diante da síndrome, que tem como característica comprometer o tempo de vida aos seus primeiros anos, é imprescindível que as famílias sejam amparadas pelos serviços e pelos profissionais de saúde no sentido de oferecer respostas resolutivas no mais curto espaço de tempo. E se o tempo urge, maior importância toma a oferta de práticas profissionais ampliadas, precisas e efetivas, que se assentem no viver e não apenas no comprometimento mortífero pela doença.

A capacidade resolutiva dos serviços de saúde assume importância capital e precisa ser repensada, ponderando os tempos protocolares no campo da saúde em relação às diferentes temporalidades do vivido por cada pessoa. Na situação de Theo, a exiguidade e imprevisibilidade do tempo da e na vida suscita reflexões sobre como os serviços têm conseguido amparar as famílias levando em conta as normalidades próprias que elas vivenciam.

Temos de refletir sobre esse tempo cronológico célere que encurta as possibilidades de vida se não for aproveitado eficaz e efetivamente no atendimen- to às suas necessidades tão peculiares. Assim os serviços precisam - mais do que oferecer respostas a problemas recortados - amparar as famílias em suas necessidades, visando apoiá-las nesse cuidado tão minuciosamente modelado por elas.

\section{Referências}

ALBANO, L. M. J. et al. Hydronephrosis in

Schinzel-Giedion syndrome: an important clue for the diagnosis. Revista do Hospital das Clínicas, São Paulo, v. 59, n. 2, p. 89-92, 2004.

ARAÚJO, C. C. M.; LACERDA, C. B. F. Examinando o desenho infantil como recurso terapêutico para o desenvolvimento de linguagem de crianças surdas. Revista da Sociedade Brasileira de Fonoaudiologia, São Paulo, v. 13, n. 2, p. 186-192, 2008.

ARAÚJO, L. F. S. et al. Diário de pesquisa e suas potencialidades na pesquisa qualitativa em saúde. Revista Brasileira de Pesquisa em Saúde, Vitória, v. 15, n. 3, p. 53-61, 2013.

AYRES, J. R. C. M. O cuidado, os modos de ser (do) humano e as práticas de saúde. In: AYRES, J. R. C. M. (Org.). Cuidado: trabalho e interação nas práticas de saúde. Rio de Janeiro: Cepesc, 2009. p. 75-105.

BELLATO, R.; ARAÚJO, L. F. S. Por uma abordagem compreensiva da experiência familiar de cuidado. Ciência, Cuidado e Saúde, Maringá, v. 14, n. 3, p. 1394-1400, 2015.

BELLATO, R. et al. Itinerários terapêuticos de famílias e redes para o cuidado na condição crônica: alguns pressupostos. In: PINHEIRO, R.; MARTINS, P. H. (Org.). Avaliação em saúde na perspectiva do usuário: abordagem multicêntrica. Rio de Janeiro: Cepesc; Recife: UFPE, 2009. p. 187 194. $376 \mathrm{p}$.

BELLATO, R. et al. Mediação e mediadores nos itinerários terapêuticos de pessoas e famílias em Mato Grosso. In: PINHEIRO, R.; MARTINS P. H. (Org.). Usuários, redes sociais, mediações e integralidade em saúde. Rio de Janeiro: Cepesc: IMS/UERJ; Recife: UFPE, 2011. p. 177-184. 
BELLATO, R. et al. The family experience of care in chronic situation. Revista da Escola de Enfermagem da USP, São Paulo, v. 5o, p. 81-88, jun. 2016. Número especial.

BRASIL. Conselho Nacional de Saúde. Resolução $\mathrm{n}^{0} 466$, de 12 de dezembro de 2012. Aprova as diretrizes e normas regulamentadoras de pesquisas envolvendo seres humanos. Diário Oficial da União, Brasília, DF, 26 set. 2013. Seção 1, p. 137 .

BRASIL. Ministério da Saúde. Portaria nº 199, de 30 de janeiro de 2014. Institui a Política Nacional de Atenção Integral às Pessoas com Doenças Raras. Diário Oficial da União. Brasília, DF, 12 fev. 2014. Seção 1, p. 44-54.

CARVALHO, E. et al. Schinzel-Giedion syndrome in two Brazilian patients: report of a novel mutation in SETBP1 and literature review of the clinical features. American Journal of Medical Genetics, Hoboken, v. 167, n. 5, p. 1039-1046, 2015. DOLINA, J. V. et al. Distinct temporalities in the breast cancer disease process. Revista da Escola de Enfermagem da USP, São Paulo, v. 48, n. 2, p. 73-8o, 2014.

GERHARDT, T. E. et al. Critérios sensíveis para dimensionar repercussões do cuidado profissional na vida de pessoas, famílias e comunidades. In: PINHEIRO, R.; SILVA JUNIOR, A. G. (Org.). Por uma sociedade cuidadora. Rio de Janeiro: Cepesc, 2010. Capítulo XX, p. 293-306.

GONZÁLEZ-LAMUÑO, D.; FUENTES, M. G. Enfermedades raras en pediatría. Anales del Sistema Sanitario de Navarra, Pamplona, v. 31, p. 21-29, 2008. Suplemento 2.

GUTIERREZ, D. M. D.; MINAYO, M. C. S. Produção de conhecimento sobre cuidados da saúde no âmbito da família. Ciência e Saúde Coletiva, Rio de Janeiro, v. 15, p. 1497-15o8, 2010. Suplemento 1.

HOISCHEN, A. et al. De novo mutations of SETBP1 cause Schinzel-Giedion syndrome. Nature Genetics, New York, v. 42, n. 6, p. 483-485, 2010. LÓPEZ-GONZÁLES, V. et al. Síndrome SchinzelGiedion: nueva mutación en SETBP1. Anales de Pediatría, Barcelona, v. 82, n. 1, p. 12-16, 2015.

MINAYO, M. C. S. O desafio do conhecimento: pesquisa qualitativa em saúde. São Paulo: Hucitec, 2010.

NEPOMUCENO, M. A. S. et al. Modos de tecitura de redes para o cuidado pela família que vivencia a condição crônica por adrenoleucodistrofia. Ciência Cuidado e Saúde, Maringá, v. 11, n. 1, p. 156-165, 2012.

PETEAN, E. et al. Dimensão espaço-tempo e os atos-atitudes de cuidado na experiência familiar. Journal of Research: Fundamental Care Online, v. 8, n. 3, p. 4738-4748, 2016.

PORTUGAL, S.; ALVES, J. P. Doenças raras e cuidado: um olhar a partir das redes sociais. In: CONGRESSO IBEROAMERICANO DE DOENÇAS RARAS, 1., 2015, Brasília, DF. Actas. Coimbra: Centro de Estudos Sociais - Universidade de Coimbra, 2015. p. 34-40.

SILVA, A. H.; BELLATO, R.; ARAÚJO, L.F.S. Cotidiano da família que experiencia a condição crônica por anemia falciforme. Revista Eletrônica de Enfermagem, Goiânia, v. 15, n. 2, p. 437-446, 2013. SOUZA, S. P. S.; LIMA, R. A. G. Condição crônica e normalidade: rumo ao movimento que amplia a potência de agir e ser feliz. Revista LatinoAmericana de Enfermagem, Ribeirão Preto, v. 15, n. 1, p. 156-164, 2007.

\section{Contribuição dos autores}

Todas as autoras participaram da concepção do estudo, análise do material empírico, redação, formatação e revisão final do texto. Além disso, Soares colaborou com o recolhimento do material empírico.

Recebido: 10/04/2016

Reapresentado: 19/08/2016

Aprovado: 25/08/2016 